\title{
Conflitos ambientais no sertão roseano: a atualização do carrancismo contra veredeiros e quilombolas em Minas Gerais
}

Environmental conflicts in the hinterland roseano: updating of the balance

against veredeiros and quilombolas in Minas Gerais

João Batista de Almeida Costa

\section{(2) OpenEdition}

12 Journals

Edição electrónica

URL: http://journals.openedition.org/aa/6688

DOI: $10.4000 / a a .6688$

ISSN: 2357-738X

Editora

Programa de Pós-Graduação em Antropologia Social (UnB)

Edição impressa

Paginação: 287-303

ISSN: 0102-4302

Refêrencia eletrónica

João Batista de Almeida Costa, «Conflitos ambientais no sertão roseano: a atualização do

carrancismo contra veredeiros e quilombolas em Minas Gerais», Anuário Antropológico [Online], v.45 n.

3 | 2020, posto online no dia 16 setembro 2020, consultado o 27 abril 2021. URL: http://

journals.openedition.org/aa/6688; DOl: https://doi.org/10.4000/aa.6688

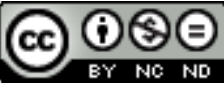

Anuário Antropológico is licensed under a Creative Commons Atribuição-Uso Não-Comercial-Proibição de realização de Obras Derivadas 4.0 International. 


\title{
Conflitos ambientais no sertão roseanos: A atualização do carrancismo contra veredeiros e quilombolas em Minas Gerais
}

\author{
Environmental conflicts in the hinterland roseano: \\ Updating of the balance against veredeiros and quilombolas in Minas Gerais \\ DOI: https://doi.org/10.4000/aa.6688
}

\begin{abstract}
João Batista de Almeida Costa • Universidade Estadual de Montes Claros - Brasil
Professor do Departamento de Política e Ciências Sociais da Universidade Estadual de Montes Claros - Unimontes. No Programa de Pós-Graduação em Antropologia Social (PPGAS) do Departamento de Antropologia (DAN) da Universidade de Brasília (UnB) concluiu o Doutorado (2003) e o Mestrado (1999). Realizou seu Bacharelado no Departamento de Ciências Sociais na Faculdade de Filosofia e Ciências Humanas (FAFICH) da Universidade Federal de Minas Gerais (UFMG) em 1984. No Programa de Pós-Graduação em Desenvolvimento Social (PPGDS) da Unimontes é vinculado à Linha de Pesquisa Movimentos Sociais, Identidade, Territorialidades.
\end{abstract}

Comunidades tradicionais veredeiras localizadas na margem esquerda do rio São Francisco e uma comunidade quilombola na margem direita do mesmo rio têm sofrido sistematicamente a opressão de organismos governamentais ambientalistas e de uma organização não governamental que as impedem de atualizar práticas tradicionais de manuseio das ecologias onde se encontram situadas. A leitura dos conflitos ambientais vivenciados atualmente nas comunidades estudadas como carrancismo se apoia na enunciação feita pelos membros dessas coletividades que utilizam esta categoria nativa temporal regional propícia para narrar suas historicidades por uma série de valores do passado distintos daqueles definidos pelos organismos ambientais. A enunciação atual dessa categoria temporal nasce da comparação entre o passado e o presente, cujos sentidos, ainda que carregados de signos semelhantes, informam o tempo dos coronéis, em que a lei do mais forte, em sua prática no sertão, era menos perversa que a dos órgãos ambientais e de uma organização não governamental na atualidade.

Conflitos ambientais. Comunidades tradicionais. Temporalidades contrastivas.
Traditional veredeiras communities located on the left bank of the São Francisco River and a quilombola community on the right bank of the same river have systematically suffered the oppression of environmental governmental organizations and a non-governmental organization that prevent them from updating traditional practices of handling the ecologies where they are located. The reading of the environmental conflicts currently experienced in the communities studied as frowning is supported by the statement made by the members of these collectivities that use this native regional temporal category that is propitious to narrate their historicities through a series of values from the past different from those defined by environmental organizations. The current enunciation of this temporal category arises from the comparison between the past and the present whose senses, although loaded with similar signs, inform the time of the colonels whose law of the strongest in their practice, in the sertão was less perverse than that of environmental agencies and a non-governmental organization today.

Environmental conflicts. Traditional communities. Contrasting temporalities. 


\section{Introdução}

Este artigo é fundamentado na perspectiva etnográfica, a partir de dados coletados e de estudos desenvolvidos nas comunidades selecionadas. Para a construção deste artigo, objetiva-se entender as compreensões por meio das quais os veredeiros e quilombolas dessas comunidades organizam suas leituras sobre os acontecimentos vivenciados pelos mesmos ao utilizar a categoria temporal carrancismo para comparar o presente à luz do passado em suas lutas a fim de garantir condições dignas de vida e de sustentabilidade para todos os membros de suas comunidades.

A noção de conflitos ambientais que orienta a leitura construída contempla grupos sociais envolvidos por considerar o plano das relações sociais conforme Acselrad (2004) e, desta forma, não opõe homem x natureza como na discussão de Floriani (2004). Também me afasto da visão de que os conflitos tenham suas raízes no desequilíbrio entre a exploração e a reposição dos recursos naturais pela escassez dos mesmos como na perspectiva de Libiszewski (1992). E, por isso, me aproximo da leitura de Turner (2004) de que o uso dos recursos naturais gera conflitos ambientais. Nesse escopo, compreendo, a partir dos casos empíricos manuseados, que aspectos imateriais devem ser enfocados, dado que as disputas entre grupos são provenientes de distintas formas de relações por eles mantidas com seu meio natural (Little, 2001). Nessa perspectiva, Acserald (2004) focaliza, por um lado, modos diferenciados de apropriação, uso e significação do território em disputa por grupos sociais distintos, considerando-os como conflitos socioambientais que se opõem. Por outro lado, Little (2006) os caracteriza como conflitos ambientais, considera-os como embates entre grupos sociais que decorrem das distintas formas de inter-relacionamento com seu meio social e natural, no qual cada grupo social possui sua forma de adaptação, ideologia e modo de vida específico que se diferencia e se confronta com as formas de outros grupos lidarem com suas realidades, formando a dimensão social e cultural do conflito.

Na temática sobre conflitos que envolvem grupos sociais e empresas privadas e instituições públicas, como soem ser os casos aqui discutidos, há duas vertentes de análises: por um lado, os mesmos são analisados como conflitos socioambientais (Little, 2001); e por outro lado, como conflitos ambientais (Acelsrad, 2004; Zhouri; Laschefski, 2010).

Embora vincule minha leitura à definição de tais conflitos como ambientais, recorro à perspectiva etnográfica de Little (2006), baseado em aspectos sociais e culturais para desenvolver a interpretação dos conflitos vivenciados nas comunidades estudadas como carrancismo, categoria temporal regional que propicia narrar as historicidades que enunciam uma série de valores do passado quase não mais existentes, conforme Correia (2002) ${ }^{1}$.

O tempo dos coronéis, ou tempo do carrancismo, é narrado como uma época de revoltas contra os processos de divisões de terra solicitados por algum fazendeiro, nos quais os sertanejos de menores condições sociais perdiam suas terras e, também, como uma época de festas, como as de Santos Reis e de Santo Antônio na Serra das Araras, em que se vivia festivamente a coletividade local e a coleti-
$\S$ A definição do espaço como Sertão Roseano é devido ao fato de que as mesmas se encontram situadas em duas regiões administrativas mineiras, como definidas pela Fundação João Pinheiro, o norte e o noroeste de Minas Gerais. E a designação se deve ao conhecimento amplo que a obra de João Guimarães Rosa propicia ao leitor no sentido de se localizar.

1 Entendo historicidade, baseado em Heidegger (2005, apud Silveira, 2016), como sendo um fenômeno constituinte do Ser ao considerar a História como o estudo do ser humano no tempo, como se a História se constituísse do conjunto de sucessões de fatos e ações passadas, ocorrendo a separação do ser do presente em relação ao passado. Para o filósofo, a historicidade própria possibilitaria que o Ser reconhecesse a natureza de enlaçamento entre o passado e o futuro no acontecer. 
vidade microrregional. Enuncia, ainda, o sistema produtivo tradicional em que o manejo das veredas, com o "esgotamento" e a queimada em tempo certo da seca, e a caçada necessária para suplementar a alimentação, eram praticados por todos. E, finalmente, e mais importante, a terra era livre e apropriável, pois "nem todas as terras eram de fazendas, e os poucos fazendeiros, ou donos, que existiam, permitiam que as pessoas morassem nas suas terras durante vários anos sem pagar pela área ocupada, ou seja, 'quem tinha terra morava, quem não tinha morava”" (Correia, 2002, p. 51).

O tempo atual, categorizado pelos membros das coletividades como carrancismo ambiental, é, também, um tempo de dominação com violências físicas e simbólicas ainda mais atroz que no tempo dos coronéis, levando ao etnocídio das comunidades tradicionais a partir da ação de organismos governamentais e uma organização não governamental. Essas ações despertam revoltas, tornam as festas "pobres pois ninguém festeja miséria", como dito por muitos comunitários. Transformações profundas ocorrem no sistema produtivo tradicional pela proibição do uso das veredas e, principalmente, pelo encurralamento dos grupos em pequenas áreas disputadas por empresas de agronegócio, unidades de conservação e grileiros, antigos policiais, a serviço de empresários. Assim, o "saudosismo" das narrativas dos comunitários é a manifestação da perversidade do tempo presente.

A utilização dessa categoria temporal pelas gentes das veredas ou quilombolas para narrar os tempos atuais emerge da comparação entre o presente e o passado. Em seu estudo, Jacinto (1998) informa que as narrativas dessa gente miúda se organizam por múltiplas referências do passado e, de forma recorrente, a enunciação do tempo do carrancismo. Ao focalizar essa temporalidade, Correia (2002) informa que alguns dos valores mencionados têm sido percebidos como um tempo melhor que o tempo presente.

$\mathrm{Na}$ atualidade, os processos sociais vividos têm sido considerados pelos membros das comunidades estudadas como o tempo dos direitos que, hierarquizados, dão mais valor à natureza do que à cultura das gentes das veredas e dos quilombos. Essas gentes são impedidas de manusearem suas práticas tradicionais ao serem consideradas pelos organismos governamentais e por uma organização não governamental como depredadores da natureza. Ou, ainda, pelo desastre ambiental causado em um afluente da margem esquerda do rio São Francisco, que tem a área das cabeceiras e até o curso médio assoreada de tal maneira que somente a copa dos buritizais fica à mostra e, assim, estrangula o sistema produtivo e impõe o manuseio de terras com baixíssima fertilidade.

Este artigo é construído a partir dos estudos em que diversos pesquisadores desenvolveram etnografias em várias localidades procurando apreender, nos processos sociais vividos, as concepções de mundo e as tradicionalidades dessas gentes miúdas. Esses pesquisadores foram orientandos de monografia, dissertação e tese ou colegas de grupo de pesquisa de que faço parte na Universidade Estadual de Montes Claros com os quais mantemos conversações em todos os nossos processos de estudos e pesquisas e com quem tenho contribuído para a construção de suas interpretações. 
Os trabalhos de campo desenvolvidos por mim estão vinculados à contratação pela Fundação Pró-Natureza - FUNATURA para realização do Inventário Nacional das Referências Culturais - INRC das manifestações culturais das comunidades veredeiras de São Francisco e Gentio. Esse trabalho foi realizado no ano de 2004, quando coordenei, como antropólogo, um grupo de funcionários desta Organização Não Governamental. Teve a duração de um ano e ocorreu em cinco idas às comunidades para levantamento de dados. Outro vínculo se refere ao Instituto Nacional de Colonização e Reforma Agrária, quando coordenei a perícia antropológica para construção de Relatórios Antropológicos de Caracterização Histórica, Econômica, Ambiental e Sócio-Cultural dos Quilombos de Lapinha, no município de Matias Cardoso, em janeiro de 2012, com permanência em campo por trinta dias. Já em Bom Jardim da Prata, no município de São Francisco, o trabalho de campo teve a duração de um ano, sendo desenvolvido em dez permanências na comunidade em curtos períodos, ao longo de 2012, após a imersão no Quilombo da Lapinha.

Em um estudo sobre o processo agonístico das comunidades veredeiras de São Francisco e Gentio, afirmo a transfiguração do tempo e do espaço dessas comunidades (COSTA, 2011) ${ }^{2}$. Por sua vez, procurando compreender a reconfiguração do poder de representação de comunidades tradicionais, dentre elas as comunidades veredeiras de Poçãozinho, Capoeirão e Breijinho (2020), apresento os processos de degradação ambiental e a recorrente perseguição policial vividos por essas comunidades. Ao estudar o sistema produtivo e sociodinâmicas ambientais na comunidade veredeira de Cabeceira de Forquilha, Gomes (2010) apresenta o abandono de manejo tradicional em decorrência das multas que a polícia ambiental impõe às famílias dessa coletividade e da minimização da capacidade produtiva.

No caso do Quilombo da Lapinha, comunidade também vazanteira, Araújo (2009) discute o intenso processo de conflito imposto pelo Instituto Estadual de Florestas à comunidade, em decorrência de incidência de sobreposição da unidade de conservação sobre o território quilombola. Na comunidade quilombola de Bom Jardim da Prata, Costa e outros (2013) apresentam, no Relatório Antropológico contratado pelo INCRA, o caso do grupo de vizinhança Santa Helena, em que o plantio de eucaliptos na cabeceira do curso d'agua de mesmo nome do Quilombo assoreou quase mais de dez metros de altura a parte superior desse rio, deixando somente as copas dos buritizais acima do areal. E na narrativa da historicidade local, que remonta ao século XVII, é afirmada a contrastividade dos sentidos incluídos na categoria tempo do carrancismo vivenciado por essa gente, como discutido por Correia (2002), quando comparam o tempo presente com os tempos anteriores.

\section{As gentes das veredas e quilombolas: suas tradicionalidades}

No espaço do curso médio do rio São Francisco, o Cerrado, a Caatinga e a Mata Seca, em suas transições ou no interior de cada um desses biomas, historicamente, as populações que aí se fixaram constituíram, em processo de coevolução com a ecologia local, sistemas diferenciados de manuseio da natureza. As denomina-
2 Este artigo resulta de trabalho de campo feito em que se utilizou a metodologia de Inventário Nacional das Referências Culturais para a FUNATURA, objetivando vincular manifestações culturais das duas comunidades veredeiras assistidas por ela após a criação do Parque Nacional Grande Sertão: Veredas em Minas Gerais. Entretanto, a compreensão do processo agonístico só ocorreu depois da orientação da pesquisa de iniciação científica de Gomes (2010). 
ções que contrastivamente informam suas identidades constituem-se identidades ecológicas como discutido por Parajuli (1996), devido aos diversos regimes de apropriação do ambiente na constituição identitária.

\section{São Francisco e Gentio}

As comunidades de São Francisco e Gentio, localidades rurais do município de Formoso, em Minas Gerais, estão situadas no entorno do Parque Nacional Grande Sertão: Veredas, tendo sido formadas pela retirada de seus moradores dos lugares onde viveram, Mato Grande e Rio Preto, até a implantação dessa unidade de conservação, e instalados em assentamentos pelo INCRA nas duas fazendas que dão denominação às suas coletividades. As duas comunidades se organizam pela articulação de noventa famílias, muitas vezes separadas pela dispersão no interior dos assentamentos; assim, parentes próximos encontram-se, muitas vezes, distanciados geográfica e ambientalmente.

Os antepassados que fundaram as duas localidades de origem foram forçados a migrarem das proximidades da cidade de Januária, em decorrência de processos de divisão de antigas fazendas, então terras devolutas, iniciados no alvorecer do século XX. Nessas divisões, somente aqueles que detinham recursos numerários puderam permanecer em sua localidade, e a grande maioria foi forçada a migrar para áreas livres sem ocupação humana. E assim, em área de terra devoluta, fixaram-se em novas localidades.

Em seu estudo, realizado antes da implantação da unidade de conservação, sobre essas populações, Jacinto (1998) informa que as coletividades se encontram dispersas dando a aparência de inexistência de povoados, havendo, entretanto, um padrão de organização espacial semelhante aos "bairros rurais". Ou seja, "existe uma unidade de agrupamento que constitui grupos rurais de vizinhança, ligados pelo sentimento de localidade, por laços de parentesco, pelo trabalho da terra, por trocas e reciprocidades" (Jacinto, 1998, p. 23).

Transferidos pelo INCRA para as fazendas São Francisco e Gentio, essa gente antes dispersa foi agrupada em dois assentamentos e reorganizou a vida social, sem poder estabelecer nas novas áreas de residência seu sistema produtivo tradicional organizado na utilização das veredas, das chapadas e das matas onde eram desenvolvidos pequenos cultivos agrícolas necessários à reprodução material das famílias, a criação de gado bovino e equino e o extrativismo. E, nem mesmo, pode construir suas casas no modo tradicional, cobertas de palhas de buritis, o que propiciava às moradias um clima ameno ante o calor externo.

Os membros dessas comunidades foram colocados em pequenos lotes em casas construídas com tijolos solo-cimento e cobertura de telhas de amianto, e foram impedidos de ter acesso às veredas, tendo que instalar seus sistemas produtivos familiares em arenosa terra de chapada, cujo solo, ínfimo, requer a introdução de insumos externos. Dessa forma foram obrigados a introduzir em seus sistemas de produção externalidades de alto custo financeiro, ou seja, assistência técnica, gradeação, adubação, além de vinculação a financiamentos bancários. Decorre daí uma queda sistemática nas condições de vida e a migração de parte das famílias 
para as cidades ou para o trabalho rural, em áreas de agronegócio, cujo salário contribui para garantir a reprodução material familiar.

O parcelamento imposto pelo INCRA desconsiderou a diversidade de solo e as condições de instalação dos sistemas produtivos de cada família, o que resultou em uma comunidade diversa, em que uns se tornaram fazendeiros e outros ficaram com terras de baixíssima qualidade, e por isto considerados "sem terra". Para um morador, "Eles estão no carrasco e carrasco não é terra para gente viver. Tem um que labuta nele, labuta, labuta e nada. Ela está sempre judiando desse um" (Costa, 2005, p. 42) ${ }^{3}$.

A leitura que o veredeiro constrói informa não apenas a cisão instaurada no interior da "coligação de famílias" vindas do Mato Grande e Rio Preto, mas também a impossibilidade da implantação do sistema de vida construído secularmente pelo impedimento de leis ambientais de ser atualizado, seja pela onipresença da FUNATURA sobre suas ações, seja pela presença ostensiva da polícia ambiental.

No choque entre a lógica veredeira e a lógica ambientalista, essa gente considera que estão deteriorando o Cerrado, pois "tem gente vivendo de palha de coco e de favela, porque é o que está dando dinheiro para cobrir a agricultura que não é mais produzida”. Dessa forma, consideram que de guardiões das veredas, que se tornaram parte da unidade de conservação, passam a depredadores dessa mesma unidade ambiental, pois "se a gente pudesse esgotar o brejo, onde a gente nunca maltratou a natureza, a gente não ia deteriorar o cerrado, principalmente as suas veredas a quem devemos tanto".

Nas leituras que fazem da historicidade de suas vidas, quando leem o acontecer que vivem, com olhos no passado procurando construir outro futuro, estão sempre comparando a vida de antes da unidade de conservação e a vida de depois de transferidos para os assentamentos. Nessa comparação, a categoria tempo do carrancismo vem sempre à tona. Nesse sentido, "no carrancismo dos coronéis a gente vivia sob a peia deles, mas tinha liberdade de produzir, de criar gado, de andar pelo mato e de fazer festa. Agora, esse carrancismo que caiu na gente é perverso demais, tirou da gente a liberdade de viver" (veredeiro, 2005, grifos meus).

\section{Cabeceira de Forquilha}

A comunidade Cabeceira de Forquilha, situada na área rural do município de Cônego Marinho, é formada por um grupo familiar composto por seis famílias nucleares que manuseiam a ecologia do lugar com práticas sociais decorrentes do modo de apreensão do ambiente.

Essas práticas são vivenciadas em suas relações de parentesco e compadrio, que lhe unem a diversos outros grupos familiares da circunvizinhança, os quais são denominados pelas populações das cercanias como gente da vereda de Forquilha. Conforme estudo sobre a comunidade, é informado que, "passaram e passam por processos de expropriação do seu modo de vida tradicional pela presença de empresários silvicultores e funcionários ambientalistas de organismos estatais" (Gomes, 2010, p. 1).
3 Durante o trabalho de campo para levantamento das referências culturais das duas coletividades, foi acordado com os moradores que jamais citaria o nome de qualquer um que tivesse sua fala textualizada no produto final contratado pela FUNATURA ou nos textos que eu viesse a publicar. Assim, mantenho o anonimato dos parceiros de conversação no tempo do trabalho de campo. 
A área onde se situa essa comunidade é dotada de um sistema hídrico formado por pequenos cursos d'água que drenam diversas veredas e deságuam no córrego Borrachudo, afluente do rio Pandeiros, cuja foz é o rio São Francisco. Para um morador do lugar, "a vereda é o lugar de tudo. Da vivência nossa, nasci e criei foi no meio desse brejo, é aqui que sei viver. Eu e minha família vivemos do trabalho na vereda (...). É da vereda que a gente tira o sustento. É lá que tudo dá” (Seu Joaquim, em Gomes, 2010, p. 25). Na compreensão do etnógrafo dessa comunidade, as veredas "nunca são vistas como adversárias que devem ser domadas para o aproveitamento máximo, como com elas se relacionam os empresários. Ou intocáveis para a fruição da paisagem na perspectiva dos ambientalistas” (Idem, ibidem).

Nesse lugar, onde tudo dá, é organizado um sistema de produção que articula apropriações diferenciadas do espaço ocupado, tendo no manejo das veredas o eixo crucial do sistema. Há, ainda, a criação de gado solto nas chapadas e o extrativismo nas três áreas manejadas, conforme Gomes (2010).

A chegada da monocultura de eucalipto para a produção de carvão vegetal, cujo destino é a indústria siderúrgica instalada em áreas de chapadas próximas à comunidade, com manejo motomecanizado em solos ínfimos, provocou o assoreamento das veredas e impossibilitou o pleno manejo das técnicas tradicionais dos veredeiros. Por outro lado, os carvoeiros derrubaram árvores para a produção de carvão vegetal que sustentaram os fornos da siderurgia mineira e fizeram desaparecer as abelhas e os frutos nativos, impossibilitando usos medicinais e alimentares dos moradores de Cabeceira de Forquilha. Há, por fim, o IBAMA e o IEF, os quais com a lógica da natureza intocada, exercem restrições às práticas produtivas e criminalizam o modo de vida tradicional veredeiro, ao aplicar multas e ameaçar de prisão aqueles que se arriscam a manejar seu sistema de produção tradicional.

\section{Poçãozinho, Capoeirão e Breijinho}

As comunidades de Poçãozinho, Capoeirão e Breijinho situam-se no município de Bonito de Minas e articulam-se com outras comunidades, todas situadas nas bacias do córrego Borrachudo e dos rios Alegre e Pandeiros. Todas são formadas por grupos de famílias nucleares organizadas por relações de parentesco e compadrio. Nas ecologias dos lugares onde se encontram fixadas, as gentes veredeiras do Território do Alegre manuseiam suas áreas com práticas sociais decorrentes do modo de apreensão do ambiente desde que seus antepassados se fixaram e desenvolveram um sistema de produção singular, articulando veredas, matas e chapadas com a agricultura, a pecuária e o extrativismo.

Em seu estudo sobre a reconfiguração do poder de representação de comunidades que lutam pelo lugar, Dayrell (2019) apresenta as estratégias produtivas das comunidades veredeiras onde desenvolveu sua etnografia, em tudo semelhante à descrita acima sobre Cabeceira de Forquilha. Na visão de um dos membros do Movimento Veredeiro, antes da emergência do conflito socioambiental, o cultivo agrícola ocorria três vezes ao ano, e muitas pessoas da mata tinham compartilhamento de áreas com o pessoal das veredas nos brejos. E então, "na vereda só 
plantava o arroz, o feijão, e no lugar mais alto, a mandioca. E milho, muito pouco, no período da seca. Na mata plantava de tudo no período das águas" (Jaime, em Dayrell, 2019, p. 280).

A chegada de empresa silvicultora, com seu plantio de eucalipto, utiliza tratores e correntões, os quais arrastam qualquer árvore, jogando-a no eito. Em seguida é feito o carvão, a gradagem de um solo ínfimo, porque arenoso, e o plantio de eucalipto. Em decorrência de multas pela destruição ambiental provocada, a empresa mudou de nome e, posteriormente, abandonou o local devido à baixa produtividade da espécie plantada. E no dizer de um morador, "o sofrimento nosso hoje, a empresa foi embora com o dinheiro e aí nós ficamos aqui com os sofrimentos (...) com a falta de água, até os animais aqui sofrem, os bichos. Então é muito triste viver numa situação desta que nós vivemos hoje de falta de água" (Dayrell, 2019, p. 285).

O sofrimento vivenciado pelas comunidades das veredas em Bonito de Minas deriva do prejuízo deixado pelas empresas silvicultoras que derrubaram a vegetação, aterraram os brejos e provocaram a diminuição das águas nos cursos d'água com a secagem das nascentes. E forçaram a criação de novas estratégias de produção que, na visão de um morador, com "a falta de chuva plantamos, mas quase não colhemos como antes, porque a chuva diminuiu, muitos rios já secaram. Hoje não podemos criar gado como antes, porque para criar tem que ter terra para plantar" (Dayrell, 2019, p. 176). E conclui sua interpretação, afirmando que o carrancismo atual é pior que o carrancismo do tempo dos coronéis e das revoltas no sertão. As revoltas atuais se organizam diferentemente do tempo passado em que indivíduos, como Antonio Dó (Braz, 2006), se insurgiram contra a expropriação das comunidades rurais por meio de divisões de terra. As comunidades, lutando por seus direitos étnicos, se organizam em entidades associativas e se articulam com o movimento social regional. Neste sentido, Dayrell (2020) estuda a reconfiguração do poder de representação de comunidades que lutam pelo lugar.

\section{Lapinha}

A comunidade remanescente de quilombo da Lapinha é formada pelos sete grupos locais ou grupos de vizinhança: Acampamento São Francisco, Barreiro da Onça, Bugi, Ilha da Ressaca, Lapinha, Saco ou Santa Efigênia e Várzea da Manga, com uma população aproximada de 379 pessoas, articuladas em 88 famílias nucleares. Toda essa população é vinculada por relações de parentesco, casamento e compadrio, que fundamentam o pertencimento de cada um à coletividade por meio do qual se compreendem como um nós em contraposição aos de fora. Importante salientar a incorporação de pessoas externas a estas relações que organizam socialmente a realidade local, os considerados chegantes, por meio de casamentos e compadrio, os quais são transformados em membros da trama de parentesco que recobre o Quilombo da Lapinha. Cabe notar que o Acampamento São Francisco é fruto da ocupação de uma área de 22 hectares da fazenda Casa Grande onde 110 famílias construíram barracos de lona preta e começaram a cultivar produtos agrícolas. Esses barracos pretos, após definição da Justiça Federal em 
favor da comunidade quilombola em processo de reintegração de posse, foram substituídos por casas feitas com adobe e seus moradores apoiados pela administração municipal. Entidades de apoio às minorias e indivíduos sensibilizados com a situação dessa gente favoreceram-lhes o acesso à energia elétrica e a um sistema simplificado de abastecimento de água, como nos outros seis grupos locais.

Em seu estudo sobre as populações beiradeiras do rio São Francisco, em parte de seu curso médio do qual o Quilombo da Lapinha é integrante, Oliveira (2015) afirma que, tradicionalmente, essas populações manejam três espaços distintos no ciclo de cheia, de vazante e de baixa do mesmo rio. No período das chuvas, essa população se transfere para as terras altas, onde cultivam milho, feijão e mandioca, dentre outros produtos. No período da baixa, retornam às margens do rio e às suas ilhas, onde foram depositados nutrientes formando diversas áreas, cujo plantio depende do tipo de solo que se consolidou após o refluxo das águas. Também utilizavam as lagoas marginais, que chamam de criadeiras, e o rio, para a pesca artesanal.

Essa população quilombola mantém sempre atualizadas informações que dão profundidades históricas às afirmações de que no período de vigência do sistema escravista ali existiu um quilombo e que seus antepassados se recusaram à escravidão e se fizeram livres e autônomos na reprodução material da vida familiar. Essa autonomia se efetivou pela articulação da pesca nas lagoas das bordas do rio e no interior da mata, com a agricultura de furado ${ }^{4} \mathrm{e}$ com a agricultura nas margens das lagoas onde se fixaram, tendo acesso, também, à caça abundante no interior da mata, tanto nas margens do rio São Francisco quanto no interior de seu hinterland.

Nos anos 1960, essa população passou por violento processo de expropriação territorial para implantação de fazendas a partir de uma ação de ordenamento fundiário realizado pela RURALMINAS, empresa pública do Estado de Minas Gerais e configurou, nos tempos atuais, a descontinuidade entre os grupos locais intercalados por fazendas de criação de gado e de agricultura com pivôs centrais.

Em fins dos anos 1990, começou a implantação das unidades de conservação como compensação aos impactos ambientais decorrentes da implantação de um mega projeto de irrigação que cerceou o acesso às lagoas, às vazantes na beira do rio e aos furados no interior da mata. As ações dos organismos ambientais obstaculizaram a comunicação dos membros dos grupos locais entre si, que passaram a ser feitas pela navegação no rio, e a atualização das práticas tradicionais de pesca nas lagoas, cultivos nas vazantes e a retomada de áreas produtivas mantidas em pousio nas terras pertencentes às famílias

E, ainda, a transumância no interior do território entre os complexos vazante e terra firme, quando se transferem para as terras altas e depois retornam com o refluxo das águas, como descrito acima. A criação do Parque Estadual da Lagoa do Cajueiro, em 1998, se sobrepõe ao território da Lapinha e encurrala as famílias quilombolas, restringindo-as a pequenas parcelas de terra na margem do rio São Francisco.

As áreas ocupadas por essa unidade de conservação integral cerceiam o acesso às lagoas, aos caminhos internos e que vinculam os grupos locais ao mundo exter-
4 Agricultura de furado (Costa Filho, 2008) é categoria êmica que informa a utilização do rebaixamento da superfície da terra após sedimentação de camada de alguma caverna no interior da rocha calcárea e que acumula água, que sendo drenada aos poucos, possibilita o plantio de vegetais mesmo no período da seca. Durante a escravidão em torno desses furados, denominação popular para dolinas, foram os locais privilegiados para a fixação de famílias que se aquilombaram. 
no, à mata para a solta do gado e coleta de frutos, plantas medicinais, madeirame para casas, cabos para ferramentas e utensílios produtivos, além dos furados para o cultivo no período das águas. Esse cerceamento tem impedido que os membros das gerações mais novas tenham contato com os encantados, como o curupira, a caipora, o dono da mata, dentre outros, e ao desencantamento do mundo.

Esses quilombolas, assim como outros grupos étnicos existentes na região, estão proibidos de exercerem suas práticas costumeiras nas vazantes da beira do rio e na retomada de roçados nas terras altas e nos baixios da beira das lagoas, bem como, de coletar produtos extrativistas na região das lagoas e nos altos. A retomada de roçados não se faz em áreas de pousio por ser considerado pelos funcionários dos órgãos ambientais como áreas novas.

Essas populações são, com frequência, inquiridas pelos funcionários do IEF e pela Polícia Florestal, que veem suas práticas tradicionais como degradantes. Para as primeiras, o acesso às lagoas é necessário para o desenvolvimento da atividade de pesca artesanal no São Francisco, pois é lá que buscam alimentos para as famílias em períodos de escassez de peixe no rio. Também se encontra interditado o extrativismo de todo tipo de madeira, fibras, cipós, plantas medicinais ou qualquer outro produto de uso costumeiro pelas famílias.

As restrições impostas com base na legislação ambiental dão origem às penalidades materiais e a constrangimentos morais por parte dos órgãos ambientais, suprimindo a liberdade e impondo a alteração de hábitos culturais com impacto sobre as estratégias reprodutivas dos grupos sociais. E, também, sobre as subjetividades dessas populações que sofrem desonras por serem perseguidas e ameaçadas pelos agentes de vigilância ambiental.

Para os grupos tradicionais da região, dentre eles os quilombolas, a prisão é lugar de ladrões e de assassinos, coisas que não são, pois exercem, apenas, as práticas culturais construídas em séculos de convivência com o ambiente em que se encontram inseridos e que ajudaram a preservar, sem saber que um dia se tornariam unidades de conservação e, como tal, transformado em mercadoria para fruição da paisagem.

\section{Bom Jardim da Prata}

O Quilombo Bom Jardim da Prata é composto por nove grupos locais: Barreira dos Índios, Bom Jardim da Prata, Catinga Grande ou Pinhãozeirinho, Mandacaru, Saco, Junco, Traz-o-Mato ou Lajeado do Acari, Porto Velho ou Manga e São Francisco de Assis. E, pelo grupo de vizinhança que articula pela contiguidade, os grupos locais Capão e Tabuleiro por um lado, e Riacho, Lajedo e Porcos, por outro lado, bem como pelo grupo de vizinhança composto pelos grupos locais Santa Helena, Corredor, Farias, Flor-de-lis e Sítio Novo.

Como o conflito socioambiental vivenciado ocorre, apenas, no grupo de vizinhança Santa Helena, passo a focalizá-lo. Nessa área do Quilombo Bom Jardim da Prata vivem oitenta e duas famílias que construíram seu sistema produtivo pela utilização das veredas para o cultivo agrícola, as terras baixas para o cultivo de mandioca, e as chapadas para a criação de gado solto e para o extrativismo. 
Com recursos oriundos dos governos federal e estadual, foram implantados projetos agropecuários e florestais nas áreas de uso comum de veredas, cerrados, matas e caatingas. Para ter instalados esses empreendimentos, a vegetação foi derrubada e carvoejada, as terras cercadas, impedindo, desde então, o tradicional uso comum para a solta do gado, caça ou coleta.

A grande maioria dos moradores perdeu as terras, total ou parcialmente, ficando, a partir de então, confinada em pequenas glebas de terra da própria família ou de parentes para onde se transferiram, assim como para as terras dos pais da noiva ou do noivo, conforme a disponibilidade de instalação de uma nova família.

Na cabeceira do rio Bom Jardim da Prata, onde se situa o grupo de vizinhança Santa Helena, verificamos que o assoreamento de terras oriundas das chapadas atingiu a copa dos buritis. Seu José Maringá lamenta a degradação das veredas: "O buriti na Prata está acabando, a água acabou, o buriti vive da água, ela secou”. Ele, em sua interpretação, apresenta as causas da degradação ambiental que impossibilitam a utilização das águas dos cursos de água para diversos fins, ou seja, onde a terra era preta, hoje é vermelha porque "fizeram carvão, plantaram eucalipto. Então, a partir de 1983 a terra começou a vermelhar" (Seu Marcelino Guedes, Santa Helena, em Costa, 2013, p. 58).

No entanto, hoje, com a ocupação "moderna" do cerrado, com a intensificação do seu uso pelos moradores que ficaram encurralados nas beiras dos córregos, as práticas tradicionais precisaram ser revisitadas, pois a maior parte das veredas, com os cerrados desmatados e as populações dos buritis alteradas, apresenta sinais visíveis de degradação, ou pelo uso intensivo, ou pelo comprometimento ocorrido nas áreas à montante, em particular com a monocultura do eucalipto.

\section{A vereda de minha leitura}

Nos estudos das comunidades acima apresentadas são focalizadas as estratégias a que as gentes nelas moradoras construíram para permanecerem em suas localidades, ainda que cerceadas pelos organismos ambientais e organização não governamental.

Em São Francisco e Gentio, a partir de 2005 a organização não governamental que onipresente define os destinos da gente veredeira transformou as suas comunidades em locais de turismo étnico para as populações urbanas, notadamente de Brasília-DF. Durante as festas de devoção que continuaram a ser realizadas, principalmente no ciclo natalino e no ciclo das fogueiras, são organizadas caravanas que se deslocam para esses dois assentamentos do INCRA.

Em Cabeceira de Forquilha, as resistências cotidianas dos veredeiros aos processos de expropriação possuem formas variadas que objetivam se opor, por diversos meios, à desqualificação, invisibilização e criminalização de suas práticas. Geram, assim, conflitos socioambientais com aqueles que invadiram sua área de reprodução material, social e cultural, tornando a natureza mercadoria para produção de riqueza e para fruição de paisagem.

Em Poçãozinho, Capoeira e Breijinho, a estratégia foi articular-se ao movimento social regional de Povos e Comunidades Tradicionais para viabilizar o acesso 
por retomadas para instaurar negociação com o Ministério Público Estadual. Em 2010, estabeleceu-se negociação da empresa que adquiriu extensas áreas de terra, entre os anos 1970/80 com financiamentos e incentivos, com a comunidade mediada pelo MPE para pagamento pelos danos ambientais promovidos. Foi proposta a devolução de uma área em torno de doze mil hectares onde se localizam seis comunidades que realizam a vigilância, fiscalizam ações de estranhos e desenvolvem campanha em outras comunidades e escolas pelo controle do fogo.

No Quilombo da Lapinha, sua população encontra-se encurralada em pequenas áreas de terra impondo-lhes condições restritivas de reprodução material, social e cultural. Os seus moradores vivem em uma área tradicionalmente ocupada quando das cheias do rio São Francisco e enfrentam processos judiciais e negociações com a estrutura governamental mineira. Além disso, sofrem ameaças da Polícia Ambiental, que por diversas vezes, aparece nos finais de tarde, quando estão reunidos, conversando sobre as atividades desenvolvidas no dia, ameaçando mulheres, crianças, idosos e homens com escopetas, AR-15 e outras armas.

Em Bom Jardim da Prata, no contexto de expropriação e de degradação ambiental em escala ampliada, um número significativo de famílias teve que reorganizar seus sistemas produtivos, utilizando, de forma mais intensiva, as terras das vazantes. Passaram também a trabalhar fora, seja como diarista seja como migrante sazonal, para ofertar a mão de obra para empresas agropecuárias em diversas regiões do país. O trabalho em condições precárias ou análogas ao trabalho escravo passou a imperar nesta porção do território norte-mineiro. Outros preferiram migrar definitivamente para a cidade de São Francisco, ou para cidades distantes, nos Estados de São Paulo, Goiás ou Distrito Federal, além de adotar o extrativismo para a comercialização e não mais para enriquecimento alimentar.

A ação sofrida na contemporaneidade pelas comunidades apresentadas acima e por outras tantas ainda não estudadas forçou mudanças no manuseio da ecologia local, dando origem a novas práticas produtivas. Penalizando a reprodução material das famílias, tal ação provou a segmentação de coletividades, em decorrência de exclusão de alguns membros que não se encontram no interior do perímetro afetado com a implantação das unidades de conservação (Jacinto, 1998).

Penaliza-se, também, moralmente, pela prisão de membros das famílias em atividades de coletas de frutos, de palmas, de andanças no interior dos parques, quando são surpreendidos pela polícia ambiental, provocando ao olhar da coletividade a desonra familiar. Passam a ser considerados, principalmente pelos vizinhos de outras coletividades, como "bandidos", conforme discutido em Costa (2005).

Essas populações fixadas secularmente nas áreas em que se encontram localizadas viveram, no passado, o mando e desmando de coronéis, e a essa temporalidade denominaram de carrancismo. Nesse tempo, as terras norte-mineiras, em sua grande maioria devolutas, eram desocupadas; e nelas os antepassados dos atuais moradores das coletividades estudadas se fixaram e fundaram seus mundi sociais.

Os sistemas produtivos implantados eram adaptados às ecologias locais, como mostrado na seção anterior. As terras, livres e apropriáveis, propiciaram a ocupação de amplas glebas e a formação de comunidades dispersas, como no caso 
de Mato Grosso e Rio Preto, narrado acima. Essas coletividades se agrupavam em momentos de festejos a seus padroeiros, em disputas simbólicas pela honra de realizarem festividades fartas em comilanças, beberagens e danças compartilhadas por todos. E todos, mesmos os coronéis que impunham pelos seus mandos e desmandos o vínculo a suas parentelas, eram incorporados na vivência coletiva.

Os valores que fundamentavam as relações entre essas gentes, no tempo do carrancismo, eram a liberdade de manuseio das terras e a implantação de sistemas produtivos adaptados às ecologias locais, a solidariedade e a reciprocidade no compartilhamento de alegrias, tristezas e necessidades e ajudas mútuas, frente às violências dos coronéis, com seu objetivo e estratégias para garantir seu mando frente a outros coronéis.

Atualmente, emerge em suas trajetórias históricas um novo tempo conformado pelo encurralamento de muitas comunidades em pequenas glebas devido à terra não ser mais livre e apropriável, à perda da autonomia na organização dos sistemas produtivos. Isso por estarem submetidos à tutela dos organismos ambientais, às mudanças nos padrões habitacionais, à perda das condições de celebrações dos santos padroeiros de famílias ou de localidades, à mudança de representação construída por outros frente às investidas policiais que impedem a atualização do conhecimento tradicional da natureza em que se encontram inseridos e, no limite, o etnocídio de um grupo étnico forçado a mudar as relações, até então interdependentes, com a ecologia do lugar onde vivem.

Na narrativa da historicidade coletiva, o saudosismo emerge como característica nascida na comparação entre o tempo do carrancismo passado frente à violência sofrida na atualidade. $\mathrm{E}$ os membros dessas comunidades passam a denominar o tempo atual como carrancismo ambiental, vinculado à violência institucionalizada com seus objetivos de conservação e proteção da natureza, bem como de implantação de monoculturas empresariais e agronegócios articulados a estratégias cuja violência ambiental se apresenta como maior perversidade em termos de expropriação e etnocídio dos saberes, dos fazeres e dos modos de vida.

Nesse tempo de carrancismo ambiental, em decorrência de ordenamento ambiental e de criação de unidades de conservação com diversos fins, dentre eles a conservação da paisagem sertaneja, a compensação ambiental pela implantação de maciços florestais de eucalipto e pela implantação de gigantesco projeto de irrigação, verifica-se a recorrente atualização da categoria temporal por meio da qual narram suas historicidades.

Frente ao carrancismo ambiental, as comunidades de identificação ecológica desenvolveram estratégias políticas, buscando encontrar soluções para dar fim aos conflitos ambientais em que foram jogados pelos organismos governamentais ou não. E a mais importante dessas estratégias é a vinculação ao movimento social regional de Povos e Comunidades Tradicionais, cuja agência tem contribuído significativamente para realizar o que denominam de "direito na prática", a partir de enfrentamento com os agentes provocadores do conflito.

Esse movimento, além dos Povos e Comunidades Tradicionais, é assessorado por uma rede sociotécnica composta por entidades da sociedade civil e das pas- 
torais católicas, por organizações não governamentais e por pesquisadores de diversas universidades brasileiras e estrangeiras. Esse movimento está vinculado a redes nacionais e internacionais de apoio às lutas das populações tradicionais, que, em seus espaços, visibilizam os conflitos sociais, políticos ou ambientais, sofridos pelas gentes miúdas do sertão norte-mineiro.

\section{Considerações finais}

Para finalizar, retomo a discussão teórica com a qual desenvolvo minha leitura. Em Acserald (2004) vimos que modos diferenciados de apropriação, de uso e de significado do território colocam em disputa grupos sociais distintos e, neste caso, as comunidades rurais sertanejas frente a organismos ambientais e organização não governamental.

E em Little (2006) aprofundo a compreensão dos conflitos ambientais vividos pelas gentes miúdas do sertão norte-mineiro, focalizando as distintas formas de inter-relacionamento com seu meio social e natural, decorrente da forma de adaptação, da ideologia e do modo de vida específico distinto daqueles que emergiram em suas vidas trazidos por organismos ambientais governamentais ou não preservadores da natureza, baseado no mito de sua intocabilidade e que formam a dimensão social e cultural do conflito que propicia aos veredeiros e quilombolas lerem suas historicidades comparando tempos distintos com a categoria tempo do carrancismo.

Nas narrativas dos moradores incorporadas neste artigo, apesar de articularem os processos vividos, para compreender o acontecer da vida atual, por meio da categoria temporal carrancismo ambiental, vejo que há recorrência de perspectivas, apresentando contradições em suas discursividades e memórias, que, certamente, não são unívocas e que não serão aqui tratadas.

Nessa comparação, são colocados frente a frente o presente e o passado, valores e penalidades, propiciando considerar os tempos dos coronéis como um tempo melhor que o tempo presente. Neste, a hierarquização de direitos dá mais valor à natureza que à cultura das gentes das veredas e dos quilombos e forçou mudanças no manuseio da ecologia local.

Resultam da ideologia da conservação e da primazia do agronegócio imposta aos veredeiros e quilombolas novas práticas produtivas que penalizam a reprodução material das famílias, provocando a segmentação de coletividades em decorrência de exclusão de alguns membros que não se encontram no interior do perímetro afetado com a implantação das unidades de conservação. E, moralmente, pela prisão de membros das famílias em atividades de coletas de frutos, de palmas, de andanças no interior dos parques quando são surpreendidos pela polícia ambiental, essas práticas provocam ao olhar da coletividade a desonra familiar. Isso porque esses membros passam a ser considerados, principalmente pelos vizinhos de outras coletividades, como "bandidos".

Nesse tempo do carrancismo ambiental, há o encurralamento de muitas comunidades em pequenas glebas devido à terra não ser mais livre e apropriável, à perda da autonomia na organização dos sistemas produtivos por serem forçados 
a abandonarem o sistema tradicional que denominam agricultura de peão, para incorporarem a agricultura de patrão, ou seja, o abandono do pouco manuseio de externalidades para a incorporação máxima das mesmas, como a assistência técnica, a motomecanização, os produtos agrícolas industrializados e, no limite, o financiamento bancário.

Essas mudanças deram fim à liberdade de vivência coletiva, empobreceram as festividades as quais passam a ser eventos para turistas assistirem, transformaram a representação de muitos moradores dado ser construída por outros frente às investidas policiais. Esse tempo do carrancismo ambiental é visto como o impedimento à atualização do conhecimento tradicional da natureza em que se encontram inseridos e, no limite, o etnocídio de um grupo étnico forçado a mudar as relações, até então interdependentes, com a ecologia do lugar onde vivem.

Recebido: 12/03/2020

Aprovado: 08/07/2020 


\section{Referências}

ACSERALD, Henri. Conflitos ambientais no Brasil. Rio de Janeiro: Fundação Heinrich Böll, 2004.

ARAÚJO, Elisa Cotta de. Nas margens do São Francisco: sociodinâmicas ambientais, expropriação territorial e afirmação étnica do Quilombo da Lapinha e dos Vazanteiros do Pau de Légua. Dissertação (Mestrado em Desenvolvimento Social) - Universidade Estadual de Montes Claros, Montes Claros, 2009.

BRAZ, Petrônio. Serrano de Pilão Arcado: a saga de Antônio Dó. São Paulo: Mundo Jurídico, 2006.

CORREIA, Cloude de Souza. Do Carrancismo ao Parque Nacional Grande Sertão Veredas: (des)organização fundiária e territorialidades. Dissertação (Mestrado em Antropologia Social) - Universidade de Brasília, Brasília, 2002.

COSTA FILHO, Aderval. Os Gurutubanos: territorialização, produção e sociabilidade em um quilombo do centro norte-mineiro. Tese (Doutorado em Antropologia Social) Universidade de Brasília, Brasília, 2008.

COSTA, João Batista de Almeida. "Tempo reversivo e espaço transfigurado: etnocídio nas veredas do sertão”. CAMPO-TERRITÓRIO: revista de geografia agrária, v. 6, n. 11, p. 161-193, 2011.

COSTA, João Batista de Almeida. Os Guardiões das Veredas do Grande Sertão: A População Tradicional do Assentamento São Francisco e Gentio, o Parque Nacional Grande Sertão Veredas e o Inventário das Referências Culturais. (Parecer). Brasília: Funatura, 2005.

COSTA, João Batista de Almeida; ARAÚJO, Elisa Cotta de; DAYRELL, Carlos Alberto; SANTOS, Fabrício Amaral Rodrigues dos; ALMEIDA, J. W. L. Relatório Antropológico de Caracterização histórica, econômica, sociocultural e ambiental da Comunidade Remanescente de Quilombo da Lapinha. Belo Horizonte: INCRA; Montes Claros: Unimontes, 2013.

COSTA, João Batista de Almeida; DAYRELL, Carlos Alberto; SANTOS, Fabrício Amaral Rodrigues dos ; ALMEIDA, J. W. L. Relatório Antropológico de Caracterização histórica, econômica, sociocultural e ambiental do Quilombo Bom Jardim da Prata. Belo Horizonte: INCRA; Montes Claros: Unimontes, 2012.

DAYRELL, Carlos Alberto. De nativos e de caboclos: reconfiguração do poder de representação de comunidades que lutam pelo lugar. Tese (Doutorado em Desenvolvimento Social) - Universidade Estadual de Montes Claros, Montes Claros, 2019.

GOMES, Luiz Guilherme Reis. Etnocídio nas Veredas do Grande Sertão: Sistemas Produtivos e Sociodinâmicas Ambientais em Cabeceira de Forquilha. Monografia (Bacharelado em Ciências Sociais / Especialização em Antropologia) - Universidade Estadual de Montes Claros, Montes Claros, 2010.

JACINTO, Andréa Borghi. Afluentes da memória: Itinerários, Taperas e Histórias no Parque Nacional Grande Sertão Veredas. Dissertação (Mestrado em Antropologia Social) - Universidade Estadual de Campinas, Campinas, 1998.

LIBISZEWSKI, Stephan. What is an environmental conflict? Zurich: Center for Security Studies, 1992.

LITTLE, Paul Elliot. Ecologia política como etnografia: um guia teórico e metodológico. Horizontes Antropológicos, v. 12, n. 25, 2006. 
LITTLE, Paul Elliot. Os conflitos socioambientais: um campo de estudo e de ação política. In: BURSZTYN, M. (Org.). A difícil sustentabilidade: política energética e conflitos ambientais. Rio de Janeiro: Garamond, 2001.

OLIVEIRA, Cláudia Luz de. Os Vazanteiros do Rio São Francisco: um estudo sobre populações tradicionais e territorialidade no Norte de Minas Gerais. Dissertação (Mestrado em Sociologia e Antropologia) - Universidade Federal de Minas Gerais, Belo Horizonte, 2005.

PARAJULI, Pramod. Ecological ethnicity in the making: developmentalist hegemonies and emergent identities in India. Identities, v. 3, n. 1-2, 1996.

SILVEIRA, Aline Dias da. Temporalidade, historicidade e presença em uma análise do prólogo do Picatrix (séc. XIII). História da Historiografia, n. 22, 2016.

TURNER, Mathews D. Political ecology and the moral dimensions of "resource conflicts": the case of farmer-herder conflicts in the Sahel. Political Geography, n. 23, 2004.

ZHOURI, Andrea; LASCHEFSKI, Klemens (Orgs.). Desenvolvimento e conflitos ambientais. Belo Horizonte: Editora UFMG, 2010. 